\title{
Detecting the emergence of novel, zoonotic viruses pathogenic to humans
}

\author{
Ronald Rosenberg
}

Received: 14 September 2014/Revised: 12 November 2014/ Accepted: 13 November 2014/Published online: 22 November 2014 (C) Springer Basel (outside the USA) 2014

\begin{abstract}
RNA viruses, with their high potential for mutation and epidemic spread, are the most common class of pathogens found as new causes of human illness. Despite great advances made in diagnostic technology since the 1950 s, the annual rate at which novel virulent viruses have been found has remained at 2-3. Most emerging viruses are zoonoses; they have jumped from mammal or bird hosts to humans. An analysis of virus discovery indicates that the small number of novel viruses discovered annually is an artifact of inadequate surveillance in tropical and subtropical countries, where even established endemic pathogens are often misdiagnosed. Many of the emerging viruses of the future are already infecting humans but remain to be uncovered by a strategy of disease surveillance in selected populations.
\end{abstract}

Keywords Emerging diseases - Zoonoses ·

Acute febrile illness - Arboviruses - Surveillance ·

Big hitter

\section{Introduction}

In common with all organisms, pathogens evolve. Every year brings reports of previously unrecognized human pathogens or of pathogens extending their geographic range, becoming less susceptible to treatment or prevention, or displaying unprecedented epidemic tendencies. As I write this an unprecedented Ebola virus epidemic threatens West Africa [1] and chikungunya, a mosquito-borne virus, which first

R. Rosenberg $(\bowtie)$

Division of Vector-Borne Diseases, Centers for Disease Control and Prevention, Rampart Road, Fort Collins, CO 80521, USA

e-mail: viruslist@cdc.gov appeared in the Western Hemisphere in November 2013, has already infected nearly 1,000,000 people there [2]. For those of us with responsibility for preventing or controlling infectious diseases, the speed with which new battles must be fought can be disconcerting. Zaire Ebola virus was first identified as a human pathogen only in 1977 and chikungunya in 1956 but neither reached pandemic magnitude until decades later. How can we be better prepared to identify emerging pathogens early? I will try to briefly examine some of the factors that influence our success in finding and characterizing previously unrecognized human viruses.

The concept of emerging diseases is relatively recent [3], even if the phenomenon is not. The definition used by the World Health Organization [4] is representative: "An emerging disease is one that has appeared in a population for the first time or that may have existed previously but is rapidly increasing in incidence or geographic range". In practice, determining if a disease is increasing in incidence or geographic range sometimes requires interpretation that might be considered arbitrary. For example, using this broad definition a recent paper [5] claimed to have identified about 400 emergent "events" between 1940 and 2012, most of which were examples of antimicrobial resistance. A more limited and less ambiguous subset of emerging pathogens will be described here: virus species first recognized to cause human illness.

\section{Three recently discovered human pathogens}

Before proceeding, it might be worth describing how three recently described pathogens were discovered and their disease characteristics. All three were first reported during the last six years and all three are generally accepted as distinct pathogenic entities causing serious human illness. 
Lujo virus

In early September 2008, a 36-year-old female resident of Lusaka, Zambia developed fulminant symptoms of an acute infection, beginning with headache and myalgia, and progressing over the next 10 days to extensive rash, facial swelling and severe sore throat $[6,7]$. By the time she was airlifted to a hospital at Johannesburg, South Africa, she had developed cerebral edema, acute respiratory distress, and renal failure. Despite intensive care, including hemodialysis, she died 14 days after her initial symptoms. Five of those who cared for her during transport to South Africa or at the Johannesburg hospital-a paramedic, two nurses and a cleaner - subsequently developed symptoms and four of these died. A previously undescribed arenavirus, lujo virus (a conflation of Lusaka and Johannesburg) was isolated from the index case and all four secondary cases [6]. The arenaviruses, which have bisegmented, single-stranded, negative-sense RNA genomes, are broadly divided phylogenetically into New World and Old World groups. Lujo belongs to the Old World group, as does Lassa virus. Typically arenaviruses have rodent reservoirs but the specific host for lujo virus has yet to be determined and how the index case was infected is unknown [7]. There have been no further cases reported.

\section{Heartland virus}

During summer, 2009, two men, aged 57 and 67 years, were admitted within a few weeks of each other to Heartland Regional Medical Center, St. Joseph, Missouri, USA, with similar symptoms of fever, fatigue, anorexia, nausea and non-bloody diarrhea. The two men were farmers who lived approximately $100 \mathrm{~km}$ distant from each other in northwestern Missouri. Both men had histories of frequent tick bite and were initially suspected to be infected with Ehrlichia chaffeensis, a tick-borne rickettsia endemic to the area. Serological and molecular testing of both, however, were negative for Ehrlichia and neither responded to antibiotics. While in hospital both men developed precipitous thrombocytopenia and leukopenia. Symptoms resolved with supportive care and both men were released from hospital 10 and 12 days after admission. Culture of specimens indicated the presence of virus, which was confirmed by electron microscopy, and subsequently a unique bunyavirus, in the group phlebovirus, was sequenced from both patients [8]. Phleboviruses are singlestranded, negative-sense RNA viruses with tripartite genomes, all of which appear to be transmitted by biting arthropods. Heartland virus is the first pathogenic phlebovirus described from the Western Hemisphere and has a $75 \%$ nucleotide homology with the severe fever with thrombocytopenia syndrome (SFTS) virus, reported from
China in 2011 [9]. Heartland virus has since been isolated from ticks and antibodies to it have been found in a variety of wild animals, including white-tailed deer (Odocoileus virginianus) and raccoons (Procyon lotor) [10]. There is no evidence for direct human to human transmission of Heartland although a number of mostly nosocomial cases have been reported for SFTS.

\section{MERS-CoV}

Between April, 2012 and late July, 2014, Middle East respiratory syndrome coronavirus (MERS-CoV) was definitively diagnosed in 837 people, 291 of whom died [11]. The focus of cases has been in Saudi Arabia, United Arab Emirates and other Middle Eastern countries; the few cases detected in Europe and North Africa appear to be travelers from the Middle East. The index case was a 60-year-old male admitted to hospital at Jeddah, Saudi Arabia in June 2012 with a recent history of fever, cough and shortness of breath [12]. At the time of admission his laboratory blood results were generally unexceptional but by 10 days post-admission his white blood cell count had increased to $23,800 / \mathrm{cu} \mathrm{mm}$ and his platelets fallen to 78,000. Antibiotic-sensitive strains of Klebsiella pneumoniae and Staphylococcus aureus were cultured from his respiratory tract but he did not respond to antibiotic therapy. Despite being on intensive support from the second day of admission, the patient died 11 days post-admission of respiratory deterioration and renal failure. Coronaviruses, which include severe acute respiratory syndrome coronavirus (SARS-CoV) and some agents of the common cold, have positive-sense, single-stranded RNA genomes and are predominately transmitted between humans by fomites. Many of the MERS-CoV cases have been nosocomial or appear to have been transmitted within families. Neutralizing antibodies to MERS-CoV have been widely found in dromedary camels [Camelus dromedarius] from the Arabian peninsula and Africa [13] and virus has been isolated from them, strengthening the evidence that they are the immediate link to emergence in humans.

Despite the differences in clinical presentation and geographical location, these three pathogens share three characteristics: all were unknown before found infecting humans, all are RNA viruses, and all have proven or putative non-human, animal sources.

\section{Animal RNA viruses are the most common source of emerging pathogens}

In a seminal study, Woolhouse et al. [14] tabulated 87 pathogens first reported to be pathogenic to humans during 1980-2005. Two-thirds of these were viruses, $85 \%$ of 
which had single-stranded RNA (ssRNA) genomes. The predominance of RNA viruses mostly owes to two characteristics. First, the rate of error during RNA replication $\left(\sim 10^{-4}\right)$ is an order of magnitude greater than that of DNA $\left(\sim 10^{-5}\right)$. RNA replication does not benefit from the proofreading capabilities of DNA polymerase or post-replication mismatch repair; consequently the potential for mutation per replication cycle is high [15] and the lack of fidelity may have limited the size of RNA genomes, many of which are in the range of 10,000-15,000 nucleotides. Second, most RNA viruses are zoonoses, that is, they were transmitted, at least initially, to humans from non-human mammal or avian hosts. Examples of RNA viruses retaining the capacity to be directly transmitted from animals to humans include influenza, Nipa, and SARS viruses, but even some viruses commonly transmitted exclusively between humans, such as HIV and hepatitis C, have likely animal origins [16]. All arthropod-borne viruses (arboviruses) are zoonoses, although some, like dengue, yellow fever, and chikungunya, have adapted to efficient vectorborne transmission between humans. Humans have been in contact with infectious animals since prehistory but their exposure accelerated with the development of livestock husbandry beginning about 15,000 years ago [17]. The growing global population has not only increased the demand for domesticated meat in the 21st $\mathrm{C}$ but has increased encroachment on areas once wild, both are trends that increase human exposure to animals and animal products [18].

\section{The rate of virus discovery}

By the end of 2010, there had been, by one tabulation [19], 213 virus species from 25 virus families incriminated as causes of human disease. More than two-thirds of these viruses $(68 \%)$ are known or presumed zoonoses. More than a quarter $(28 \%)$ were first described from non-human mammals, birds or blood-feeding arthropods 1-77 years before being recognized as human pathogens. Indeed, the first vertebrate virus described, the cause of foot and mouth disease, was isolated from a cow in 1897 [20] but conclusively shown to cause human disease only in 1954 [21]. The dates of discovery, regardless of host, are plotted in Fig. 1a. The rate at which virulent viruses have been discovered has been governed by two equally important factors: the ability of existing technology to detect and discriminate between viruses, and the ability to collect specimens potentially containing novel viruses.

Initially, the lack of methods for the laboratory cultivation of viruses, which require cells for replication, prevented their isolation for study. Early characterization as a virus depended mainly on demonstration that a

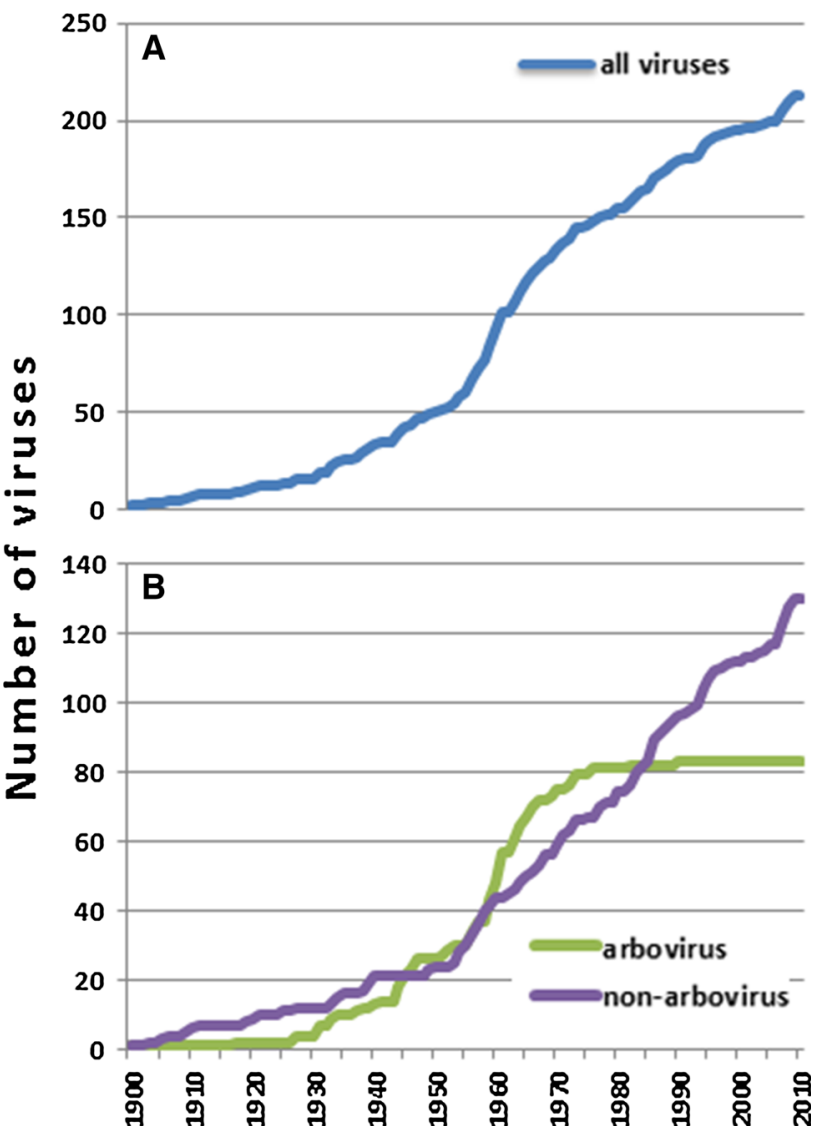

Fig. 1 a The cumulative number of viruses discovered annually. The discovery date might precede the incrimination of the virus as a cause of human disease, as known by 2010. b Comparison of the cumulative rate of discovery of arboviruses and non-arboviruses

filterable agent smaller than bacteria was responsible for transmissible disease. Until the late-1930s, when embryonated chicken eggs and suckling mice began to be used commonly to culture animal viruses, only 26 of the viruses now known to be pathogenic had been described. The rate of discovery again accelerated after the introduction of in vitro cell culture in 1949 (Fig. 1a). The mean annual rate of virus discovery during 1950-1959 was 3.3. During this period methods for antigentically typing viruses using panels of antibodies were refined and came into wide use. There was a striking increase in the number of novel viruses described during 1960-1969 to 4.9/year. This was followed, however, by a sudden deceleration in the rate of discovery to only about $2 /$ year, which persisted through 2010, despite the availability of increasingly powerful methods for genomic characterization, such as polymerase chain reaction (PCR) from the mid-1980s and, more recently, high-throughput, parallelized ("next-generation") sequencing.

Vertebrate viruses can be sorted into two broad categories: those directly transmissible between humans or 
between animals and humans, and the arboviruses, which require the mediation of blood-feeding arthropod vectors, such as mosquitoes or ticks; $39 \%$ (83) of pathogenic viruses are transmitted to humans only by arthropod vectors. The sudden, transitory increase in rate during 1960-1969 has been shown [19] to be because the rates of discovery of these two classes differed (Fig. 1b). Before 1950 the rates for the two were the same and each comprised about half the pathogenic viruses. After 1950, however, the trends of the two classes of virus diverged. While about two non-arboviruses were discovered each year between 1950 and 2010, the arboviruses dramatically increased during 1960-1969, only to fall equally dramatically to nearly zero by 1980 . During $1960-1969$ twice as many arboviruses (32) were discovered than non-arboviruses (15); by contrast, during 1981-2010, only 2 arboviruses were discovered compared to 57 non-arboviruses. The difference in the rates for the two classes highlights the important role that strategies for specimen collection play in the recognition of novel pathogens [19].

\section{The Rockefeller Foundation as "big hitter"}

The efflorescence of arbovirus discovery during 1960-1969 coincided with activities at tropical field research stations sponsored by the Rockefeller Foundation (RF). During its investigations on yellow fever during 1916-1940 the RF had circumstantially discovered several novel arboviruses, including West Nile virus. In 1951 it began a 15-year program of arbovirus research in Brazil, Trinidad, Colombia, Nigeria, South Africa, Egypt and India [22]. All the field stations were located in tropical or sub-tropical countries and all carried out an integrated strategy that attempted to discover viruses from humans, vertebrate animals and biting arthropods. Of the 83 arboviruses discovered by the end of 2010, 35 (42\%) were discovered by RF staff, 23 of those during 1951-1969. In comparison, the single most successful institutional discoverer of non-arboviruses, the United States National Institutes of Health, described 12 of 130 (9\%). The RF protocol, which was the model for several other institutions, including the Institut Pasteur, was directly responsible for two additional characteristics differentiating arbovirus from non-arbovirus discovery. Although $68 \%$ of all non-arboviruses were discovered in Europe or the USA, $67 \%$ of all arboviruses were discovered in SubSaharan Africa, Latin America/Caribbean, or Egypt/India/ Near East (Fig. 2). Second, $33 \%$ of arboviruses were first isolated from arthropods, a consequence of systematic vector collections. The predetermined cessation, by 1970 , of most RF support for international arbovirus researchincluding sponsorship of reference collections, conferences, new technology and reagents-was soon followed by a rapid, worldwide decline in arbovirus discovery (Fig. 1b). The East African Virus Research Institute, for example, which was founded by RF in 1935 , isolated 5 arboviruses after direct RF administration ended in 1952, but none after the general RF program closed in 1965.

The disproportionate productivity of RF resembles that of especially effective individual discoverers of plant species [23]. Those botanical "big hitters" combined technical expertise and persistence over many years with concentration in a limited geographic area where they had gained deep knowledge. The RF was committed to a long-term strategy founded on five components. First, it chose study sites where it had evidence that arbovirus diversity would be high. These were mostly tropical and contained forested and rural areas. They chose countries where a professional work force could be recruited and where it was hoped the work would be sustained after the RF departed. Second, the program concentrated only on one subclass of pathogens, the arboviruses. Despite the wide competence of the professional staff, few reports were published dealing with local diseases other than arboviral. Third, the research strategy called for long-term commitment. RF staff, including expatriates, typically lived on site and implemented projects for years, allowing for continuity of not only research but training. Fourth, the program was integrative. Human, animal and vector investigations were simultaneously pursued. Because all scientists worked in a single unit connections between human virus isolates and those from animals or vectors were readily made. On the other hand, for many viruses isolated from animals or arthropods there has yet to be a link to human infection [24]. And fifth, each unit was self-contained. Each was capable of conducting both specimen collection and sophisticated laboratory analyses.

How many pathogenic viruses remain to be discovered?

Mathematical methods for extrapolating from historical rates of discovery to estimate the pool of yet to be discovered organisms in a given taxon tend to be accurate only after most species have already been discovered [25]. The fundamental weakness of these computations, which generally rely on analysis of cumulative frequency curves, is the assumption that the numbers of organisms known at a given time are the result of methods of discovery that have been consistent everyplace and throughout time. The increased rate of virus discovery during 1955-1970 was largely due to the temporary efforts of the RF, a "big hitter" [23], whose combination of active surveillance, geographic specialization, and integrated approach remains atypical.

In contrast to sophisticated computations, a recently published prediction that a minimum of 320,000 
Fig. 2 Comparison of regions in which arboviruses and nonarboviruses were discovered

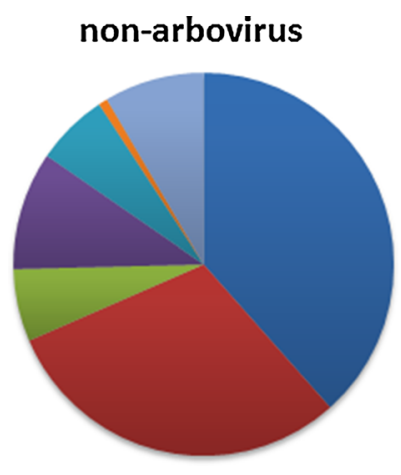

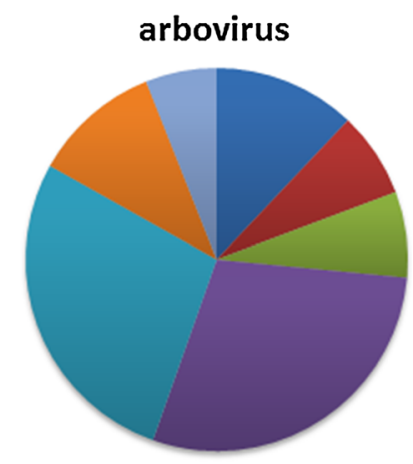

mammalian viruses of 9 families remain to be discovered was based on a simple arithmetical calculation using data from a single study [26]. Considering how few new, virulent viruses are found every year, the potential for any of 320,000 viruses jumping to humans and being discovered would then be very low $\left(6.25 \times 10^{-6}\right)$. The authors used degenerate, virus-family-level primers to amplify genomic segments from specimens of feces, urine, and throat swabs collected from the bat species Pteropus giganteus in Bangladesh. Amplicons were as short as $250 \mathrm{bp}$ and no biological information was obtained. They found 55 viruses (and statistically surmised an additional three existed), some of which might be novel, belonging to seven virus families. In calculating a number for the universe of viruses yet to be found they speculated that each of the known 5,486 mammal species will host an average 58 unique viruses, unshared with other species. The authors concede that there is little evidence to support these presumptions. A single subtropical bat species hardly represents all mammal species and indeed many viruses are known to infect more than one species; they tested for only 9 of the 25 virus families pathogenic to humans. Ultimately, the number of viruses remaining to be discovered is irrelevant if, as expected, there are many and they continue to rapidly evolve.

\section{Predicting emergent potential}

The discovery of a virus can long predate its emergence as a recognized public health threat. The discovery of Zika virus in a monkey in Uganda preceded its first incrimination as the cause of a human epidemic $-12,000 \mathrm{~km}$ distant in Micronesia-by 70 years [27]. As noted above, the availability of ever more powerful molecular techniques is substantially increasing the catalog of distinct viruses found in nature but the number found annually to be pathogenic to humans rarely exceeds a few each year. Is it feasible to predict which animal viruses have the potential to cause disease in humans?
Steps to emergence

The steps by which a virus might emerge from exclusively animal hosts are schematically depicted in Fig. 3. At the most preliminary level (Tier 1) viruses circulate within mammals and birds, not necessarily causing disease, before some opportunistically infect humans (Tier 2). Typical human-animal contact includes husbandry, capture of wild animals for food, and exposure to animal fomites or waste, as may happen in bat infested environments. Indirect exposure via arthropods must be frequent, as evidenced by the large proportion of pathogenic viruses that are vectorborne [19]. In most instances these Tier 2, opportunistic infections are dead ends or remain rare events because the pathogen is not well adapted to transmission between humans (e.g., Crimean-Congo hemorrhagic fever virus) or because the type of contact between infected animals and humans is uncommon (e.g., sealpox virus). A small but

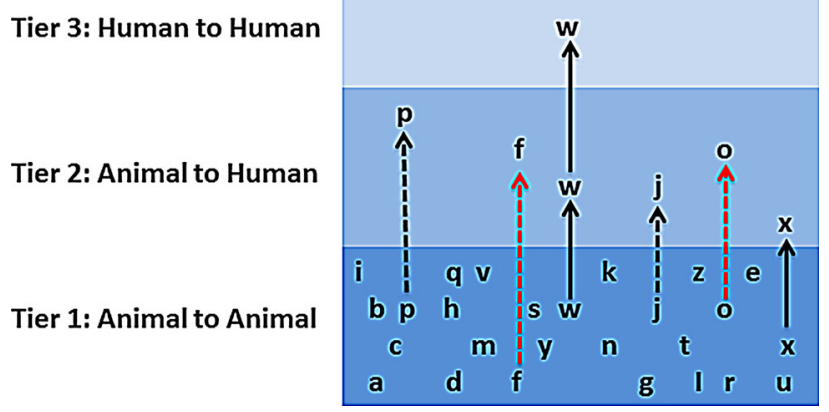

Fig. 3 Schematic of the emergence of zoonotic viruses as human pathogens. In Tier 1, viruses are only transmitted among sub-human animals. In Tier 2, viruses infect humans, but only directly from animals. Some animal viruses (solid arrows), like West Nile, can fuel zoonotic epidemics. Others, like hantaviruses, are frequent but subepidemic causes of human illness (dashed black arrows), while many, like sealpox, are rare (dashed red arrows). In Tier 3, zoonotic viruses have acquired the ability to be transmitted between humans without the contribution of the animal host. In some cases (W) a virus might leap directly to Tier 3 or transition through Tier 2 
significant group of zoonotic viruses, including Rift Valley fever, Nipah and West Nile viruses, are capable of instigating human epidemics without ever adapting to humanhuman transmission.

Theoretically even sub-epidemic $\left(R_{\mathrm{O}}<1\right)$ transmission can favor mutations that will enhance future transmission [28]. In rare instances (Tier 3) pathogens do evolve to allow human-human transmission (e.g., HIV) or appear to already posses that capacity (e.g., MERS-CoV, lujo). Some viruses maintain animal-animal and animal-human cycles but are mostly propagated by human-human transmission (e.g., chikungunya, Zika). The geographically limited sylvatic cycles of dengue in West Africa and Southeast Asia account for a tiny percentage of the estimated 390 million infections annually [29].

\section{Biological determinants}

Human contact with an animal virus does not ensure infection. Among the biological barriers for the virus are finding a route of entry, evading general immune defenses, invading host cells, replicating sufficient numbers before specific immune responses are mounted, and finding a route to the next host. Aerosol delivery, for example, greatly enhances transmissibility but efficiency depends on the anatomical site within the respiratory system of the invaded cells [30, 31]. Arbovirus transmission, in which the vector amplifies, transports and inoculates the virus into humans, can be enhanced by viral mutations that increase the potential for successfully infecting the vector [32, 33] or animal host [34] without altering its virulence to humans. Much recent research has focused on identifying determinants essential for viral invasion of host cells and how modification of the viral ligands might increase their ability for interspecies infectivity [34].

It is not yet possible on the evidence of sequence alone to predict with confidence the probability of an animal virus transitioning to humans. In general, vertebrate specificity greatly limits the ability of viruses adapted to one species to invade similar cells in another, distant species. Influenza A is the most studied and best understood of the few viruses that frequently jump from animals to humans. A number of mutations have been identified that enhance infectivity. These include substitutions in the hemagglutinin (HA) protein receptor binding sites that enable the virus to exploit sialylated glycan receptors on respiratory cells belonging to other species [35]. For example, two nonsynonymous base changes in the HA receptor binding sites of avian $\mathrm{H} 2$ and $\mathrm{H} 3$ viruses, which converted their specificity from the avian $\alpha 2,3-\mathrm{SA}$ to human $\alpha 2,6-\mathrm{SA}$, led to the 1957 pandemic of H2N2 and the 1968 pandemic of H3N2 [36]. Much current research on the determinants of influenza specificity is experimental and its extension to complex natural transmission of other virus families remains to be tested. Understanding how such adaptability works could focus our attention on those virus families or species with the greatest chance of infecting humans but how this knowledge could be used more specifically to identify potential threats to humans among animal viruses, as has recently been proposed [5], is unclear.

Geographical bias, human behavior and likelihood of contact

Species richness of mammals and birds is greatest at the equator, thinning toward the poles [37]; mosquitoes [38] and ticks [39] appear to follow a similar latitudinal species diversity gradient. Pathogen species are also richer in the tropics than in temperate zones [40] although, as has been ruefully pointed out, "The fact that warbler species distributions are better understood than the distribution of human pathogens is a gap that clearly deserves research attention" [41]. There is a strong association between mammal and pathogen richness but mammal diversity appears to be an indicator rather than the cause of pathogen diversity [41]. Pathogens that maintain external life cycles, for example vector-borne and helminthic, which are directly susceptible to variability in precipitation, tend to be more geographically restricted to the tropics than those directly transmissible between people, such as influenza [40]. Environmental barriers to dispersion can be circumvented. Monkeypox virus, whose natural transmission is largely restricted to parts of equatorial Africa by the range of its natural rodent hosts, has demonstrated the ability to make use of new hosts in temperate zones [42] and a number of arboviruses, such as chikungunya, dengue and Zika viruses, have widely expanded their natural ranges as their principal vectors have [43]. The RF selection of field sites in 1950 was based on the relatively greater diversity of arboviruses found during the preceding 35 years in tropical countries and it can be argued that their success in discovering new viruses owed as much to this factor as their choice of integrated, active surveillance. As would be expected, there appears to be a correlation between zones of species richness and frequency of reported vector-borne and zoonotic emerging disease events [44].

The species richness of the tropics suggests that human populations there are exposed to greater risk and that they are fertile grounds for virus mutation. Certain behaviors common to some regions, such as the harvesting of wild animals for food, aggravate that risk. The lack of housing barriers to rodents, bats and arthropod vectors are major vulnerabilities to pathogens carried by them. Environmental and sanitation deficiencies also increase risk to enteric and vector-borne viruses; in the absence of dependable water supply, many people, for example, are 
forced to store containers of water that provide breeding for the virus-carrying mosquitoes. Most importantly, as Dunn et al. [41] have shown, countries with the highest pathogen richness spend the least per capita on health care, and there is an inverse correlation between investment in public health and pathogen prevalence, independent of species richness.

\section{Modeling "hot spots"}

Because of the obvious link between the abundance of novel viruses and the tropics, geospatial modeling could help target areas for surveillance. There is a tradition of developing and using models to identify those areas of the world whose species richness is most in need of conservation [37, 45] and recently attempts have been made to use models to identify areas most liable to spawn emerging diseases [5, 44]. Considering the association between mammal and pathogen species richness there can be expected to be some overlap between the two sets of "hot spots". The predictive robustness of a model depends not only on the algorithms used but in the choice and weighting of variables, and the representativeness and validity of the data. For example, a widely cited model [5, 44], which chooses "the original case or cluster of cases representing an infectious disease emerging (during 1940-2004) in human populations for the first time", lists only 61 of 168 viruses first described as infecting humans during that period [19]. On the other hand it credits the first occurrence of a number of viruses described years earlier to the period 1940-2004; these include measles, influenza A, and rabies, assigning to each a single, arbitrary origination location (US, Hong Kong, and Costa Rica, respectively) for modeling geospatial associations. Because this model also lumps a variety of emerging disease types, including many examples of antimicrobial resistance, population density is a major factor, which might explain the higher likelihood for emergent events it assigns to India and Java than to the Amazon or equatorial Africa, where so many novel viruses have been discovered.

Modeling has been more successful for single pathogens for which large amounts of specific data have been collected, such as for dengue [46] or malaria [47]. Associating disease prevalence in a limited area with well-characterized environmental attributes, as has been done for plague bacteria (Yersinia pestis) in Uganda, can be used to predict areas potentially at risk that would be difficult to collect data from, such as large plague-prone tracts of the neighboring Democratic Republic of Congo [48]. Because many of the arbovirus species are known only from places where long-term field operations were established by the RF, Institut Pasteur, and others, and because those sites were selected for logistical and political realities as well as scientific interest, their usefulness in modeling is still limited.

\section{Surveillance for emerging pathogens: the problem of knowing the unknown}

Human surveillance

Successful surveillance depends on how and where one looks. Ideally, an emerging virus will be detected at its source and contained before spreading. This ideal requires, however, extensive networks of alert health care providers, adequate laboratory resources, and an effective method for communicating results to an authority capable of responding. It also assumes that a zoonotic virus will not be spread by animal hosts impossible to control, as was the case with the avian arbovirus, West Nile.

In practice, human disease surveillance raises an alarm only after an arbitrary number of seemingly related, serious cases are reported and arouse attention. Generally, number of cases and length of time to detection are least for anticipated pathogens with distinct presentations, such as poliovirus presenting with acute flaccid paralysis. In countries with rudimentary public health systems that threshold might be reached for unexpected pathogens only after the number of cases reaches epidemic proportions impossible to ignore, as the recent epidemic of Ebola virus in West Africa demonstrates. Many viral disease cases present as clinically indistinguishable acute febrile illnesses (AFI) or with symptoms so mild the patient does not seek attention. Cases with neurological involvement or systemic bleeding can also be difficult to diagnose clinically without adequate laboratory support. In those tropical areas most likely to spawn emerging viruses, AFI will be misdiagnosed or undiagnosed in at least $50 \%$ of patients [49-52]. Overlooking novel pathogens as the cause of nonspecific symptoms is not confined to developing countries: it is likely Heartland virus was a cause of illness in the USA long before it was characterized in 2012. Nevertheless, the probability that more undescribed viruses infect humans in the tropics seems to be greater. It is likely, therefore, that many emerging diseases due to novel viruses will be overlooked, especially at Tier 2, until they become epidemic, are transported to countries with more sensitive surveillance, or are discovered by chance.

Laboratory support for clinicians is critically deficient nearly everywhere in the rural tropics. The first step in determining if an illness might be caused by a rare or unknown virus is to eliminate the possibility of pathogens known to be endemic. Simple, relatively accurate rapid diagnostic tests (RDTs) are available for a few common causes of AFI, notably malaria, but tests for most viruses 
require not only equipment, such as ELISA readers, but modest, dependable infrastructural support-electric power, clean water, cold storage-rarely available outside major cities. Poor roads often make the timely, proper transport of specimens to centers with laboratory capacity impractical. Even in cities, many hospitals and government laboratories do not have the basic equipment, fresh reagents or accurate testing protocols to assay for most common endemic pathogens.

Should laboratory capability be available to eliminate most known etiologies for the disease observed, description of a novel pathogen typically requires both biological and molecular characterization [53]. Recovery of viable virus for culture and histological evidence of pathology remain fundamental steps establishing causality. The increasing power and availability of rapid, next-generation sequencing has made whole-genome analysis an increasingly routine and important part of describing novel viruses but because of the large number of commensal species found in the human virome [54], linking a novel genome with virulence will be tentative without supporting biological evidence. For example, WU and KI polyomaviruses, isolated in the mid-2000s from children suffering from acute respiratory infections and tentatively included in the list of human pathogens [19], have yet to be proven causal of illness [55].

Our ability to detect and characterize novel pathogenic viruses in hot spot locations lags behind global systems that have arisen to report and respond to unusual occurrences. The International Health Regulations (IHR) of the World Health Organization (WHO) binds 196 countries to plans to improve their ability to detect and respond to outbreaks, and the Global Outbreak Alert and Response Network (GOARN) of WHO helps organize international response to public health emergencies. Open source networks for reporting outbreaks include the Program for Monitoring Emerging Diseases (ProMED-mail), a free, internet-based system for disseminating information posted by 40,000 professional contributors in 185 countries, and HealthMap, which collects and continuously updates disease outbreak data from a variety of public sources, including news services. Many of these reports seem never to be investigated or resolved. The full value of these systems can only be attained if provided with accurate information.

\section{Animal surveillance}

Considering the barriers to obtaining human surveillance data, it has been proposed [5] that monitoring animal populations at sentinel locations could alert us to risk from viruses with pandemic potential. For such a plan to be feasible for emerging viruses it would be necessary to judge the potential risk posed by a virus not yet known to infect humans. Epizootic disease in livestock or wild animals is used as a threat indicator for some known zoonotic viruses, such as influenza, Rift Valley Fever virus, and West Nile virus, but there is no assurance that an agent potentially pathogenic to humans will cause noticeable disease in animal hosts. Coronaviruses closely related and putatively ancestral to SARS virus, for example, seem not to cause disease in host bats [56]. The extent of animal disease surveillance is also far less in the tropics than even the poorest human clinical networks so the likelihood of recognizing an unusual event is less. Periodic sampling of animals can discover novel viruses but is too infrequent and limited to be surveillance. Considerable attention has been given to human contact with bush meat, or animals captured for food [5]. While harvesting and slaughtering wild animals appear to have provided the mechanism by which some important pathogens have emerged, such as HIV and SARS, it has not played a role in the emergence of many others, including the three examples discussed in this paper: lujo, Heartland and MERS-CoV. Vectors obviate the need of direct human-mammal or human-bird contact and can move viruses across ecological zones. Sequencing and cataloging the viruses of animals in selected areas can provide valuable insight to transmission dynamics and phylogenetics but, as discussed, cannot yet be used to predict. One must wonder if the US $\$ 6.3$ billion proposed to catalog mammalian viruses not yet known to be pernicious [26] would not be better spent on developing more suitable diagnostic tests for humans in remote areas most liable to emerging pathogen risk or on conducting sentinel human surveillance. Ultimately, the best indication that a pathogen has the ability to jump to humans is finding it in humans [57].

Integrated surveillance at sentinel sites

Although there is not a strong rationale for conducting autonomous searches for potentially pathogenic viruses in animal populations, there is much value in animal investigations in support of surveillance for infectious diseases in selected, sentinel human populations. The discovery of lujo virus in a human, for example, should direct our attention to its epidemiology and ecology in the area where we suspect exposure occurred. Had lujo been discovered in an animal instead, its significance as a pathogen would have been speculative until the detection of the first human case. The integrative, long-term approach of the RF can serve as a model but with primary focus on conducting population-based surveillance for acute illness. Concomitant ecological profiling and virological studies in arthropods, mammals and birds can more quickly clarify the epidemiology of any novel viruses discovered in the human population. 


\section{Conclusions}

The zoonotic viruses pathogenic to humans represent a small but unknown proportion of those infecting mammals and birds. From this constantly evolving universe of vertebrate viruses two or three are recognized every year to have broken the species barrier, a remarkably small number considering the frequent contact between humans and animals, and the high adaptability of RNA viruses. While most of these novel, emergent viruses have inconsequential public health significance, some, such as MERS-CoV or lujo, have obvious destructive potential. What is the best strategy for identifying and limiting the menace from novel, zoonotic viruses? Identifying potential pathogens before they leap to humans (Tier 1) would seem ideal but is impractical. The determinants of pathogenicity are complex and poorly understood, while a system for wildlife or livestock surveillance in those areas with conditions most conducive to emergence cannot anytime soon reach a scale or effectiveness to be pragmatic.

It is likely that yet to be recognized viruses already infecting humans will be sources of disease outbreaks of varying magnitude in the future. These Tier 2 infections can be uncovered as part of comprehensive, investigative surveillance in human populations at risk. In the near term this would be best accomplished in most places through specially designed sentinel surveillance sites. Modeling might at some point provide guidance for site selection but too narrow a definition for target sites (e.g., bush meat markets) will be self-defeating. By identifying and eliminating poorly appreciated endemic agents, investigations can then focus on illnesses with unresolved etiologies. Unlike investigations directed at animal populations there would be a tangible, immediate improvement in the health of the subject communities. Complimentary studies of vectors and animals, as pioneered by the Rockefeller Foundation, would prepare for epidemiological investigations of those zoonoses uncovered but the primary focus must be on humans. Ultimately, one hopes, surveillance for emerging zoonoses will be a part of improved health care systems throughout the world.

\section{References}

1. World Health Organization (2014) Global alert and response: Ebola virus disease. http://www.who.int/csr/disease/ebola/en/. Accessed 20 August 2014

2. Centers for Disease Control and Prevention (2014) Chikungunya virus in the Americas. http://www.cdc.gov/chikungunya/geo/ americas.html. Accessed 20 August 2014

3. Lederberg J, Shope RE, Oaks SC (1992) Emerging infections: microbial threats to health in the United States. National Academies Press, Washington
4. World Health Organization (2014) Health topics: Emerging Diseases. http://www.who.int/topics/emerging_diseases/en/. Accessed 20 August 2014

5. Morse SS, Mazet JA, Woolhouse M, Parrish CR, Carroll D, Karesh WB, Zambrana-Torrelio C, Lipkin WI, Daszak P (2012) Prediction and prevention of the next pandemic zoonosis. Lancet 380(9857):1956-1965

6. Paweska JT, Sewlall NH, Ksiazek TG, Blumberg LH, Hale MJ, Lipkin WI, Weyer J, Nichol ST, Rollin PE, McMullan LK, Paddock CD, Briese T, Mnyaluza J, Dinh TH, Mukonka V, Ching P, Duse A, Richards G, de Jong G, Cohen C, Ikalafeng B, Mugero C, Asomugha C, Malotle MM, Nteo DM, Misiani E, Swanepoel R, Zaki SR (2009) Nosocomial outbreak of novel arenavirus infection, southern Africa. Emerg Infect Dis 15(10):1598-1602

7. Briese T, Paweska JT, McMullan LK, Hutchison SK, Street C, Palacios G, Khristova ML, Weyer J, Swanepoel R, Egholm M, Nichol ST, Lipkin WI (2009) Genetic detection and characterization of Lujo virus, a new hemorrhagic fever-associated arenavirus from southern Africa. PLoS Pathog 5:e1000455. doi:10.1371/journal.ppat.1000455

8. McMullan LK, Folk SM, Kelly AJ, MacNeil A, Goldsmith CS, Metcalfe MG, Batten BC, Albariño CG, Zaki SR, Rollin PE, Nicholson WL, Nichol ST (2012) A new phlebovirus associated with severe febrile illness in Missouri. N Engl J Med 367(9): 834-841

9. Yu XJ, Liang MF, Zhang SY, Liu Y, Li JD, Sun YL, Zhang L, Zhang QF, Popov VL, Li C, Qu J, Li Q, Zhang YP, Hai R, Wu W, Wang Q, Zhan FX, Wang XJ, Kan B, Wang SW, Wan KL, Jing HQ, Lu JX, Yin WW, Zhou H, Guan XH, Liu JF, Bi ZQ, Liu GH, Ren J, Wang H, Zhao Z, Song JD, He JR, Wan T, Zhang JS, Fu XP, Sun LN, Dong XP, Feng ZJ, Yang WZ, Hong T, Zhang Y, Walker DH, Wang Y, Li DX (2011) Fever with thrombocytopenia associated with a novel bunyavirus in China. N Engl J Med 364(16):1523-1532

10. Savage HM, Godsey MS Jr, Lambert A, Panella NA, Burkhalter KL, Harmon JR, Lash RR, Ashley DC, Nicholson WL (2013) First detection of heartland virus (Bunyaviridae: Phlebovirus) from field collected arthropods. Am J Trop Med Hyg 89(3): 445-452. doi:10.4269/ajtmh.13-0209

11. World Health Organization (2014) Middle East respiratory syndrome coronavirus (MERS-CoV) - update. http://www.who.int/ csr/don/2014_07_23_mers/en/. Accessed 12 September 2014

12. Zaki AM, van Boheemen S, Bestebroer TM, Osterhaus AD, Fouchier RA (2012) Isolation of a novel coronavirus from a man with pneumonia in Saudi Arabia. N Engl J Med 367(19):1814-1820

13. Raj VS, Farag EA, Reusken CB, Lamers MM, Pas SD, Voermans J, Smits SL, Osterhaus AD, Al-Mawlawi N, Al-Romaihi HE, AlHajri MM, El-Sayed AM, Mohran KA, Ghobashy H, Alhajri F, Al-Thani M, Al-Marri SA, El-Maghraby MM, Koopmans MP, Haagmans BL (2014) Isolation of MERS Coronavirus from a Dromedary Camel, Qatar, 2014. Emerg Infect Dis 20(8): 1339-1342. doi:10.3201/eid2008.140663

14. Woolhouse M, Gaunt E (2007) Ecological origins of novel human pathogens. Crit Rev Microbiol 33:231-242

15. Drake JW, Holland JJ (1999) Mutation rates among RNA viruses. Proc Natl Acad Sci USA 96:13910-13913

16. Wolfe ND, Dunavan CP, Diamond J (2007) Origins of major human infectious diseases. Nature 447(7142):279-283

17. Diamond J (1999) Guns, Germs, and Steel: The Fates of Human Societies. Norton, New York

18. McMichael MJ (2004) Environmental and social influences on emerging infectious diseases: past, present and future. Phil Trans R Soc Lond B 359:1049-1058

19. Rosenberg R, Johansson MA, Powers AM, Miller BR (2013) Search strategy has influenced the discovery rate of human viruses. Proc Natl Acad Sci U S A 110(34):13961-13964 
20. Loeffler F, Frosch P (1897) Berichte der Kommission zur Erforschung der Maul-und Klauenseuche bei dem Institut für Infektionskrankheiten in Berlin. Zent Bakt Parasitkde Abt I 23:371-391

21. Vetterlein W (1954) Das klinische bild der maul-undklauenseuche beim menschen, aufgestelt aus den bisher experimentell gesicherten erkrankungen. Arch Exp Veterinarmed 8:541-564

22. Downs WG (1982) The Rockefeller Foundation virus program:1951-1971 with update to 1981. Annu Rev Med 33:1-29

23. Bebber DP, Carine MA, Davidse G, Harris DJ, Haston EM, Penn MG, Cafferty S, Wood JR, Scotland RW (2012) Big hitting collectors make massive and disproportionate contribution to the discovery of plant species. Proc R Soc B 279:2269-2274

24. Centers for disease control and prevention, international catalog of arboviruses including certain other viruses of vertebrates. (http://wwwn.cdc.gov/arbocat/index.asp)

25. Bebber DP, Marriott FH, Gaston KJ, Harris SA, Scotland RW (2007) Predicting unknown species numbers using discovery curves. Proc Biol Sci 274:1651-1658

26. Anthony SJ, Epstein JH, Murray KA, Navarrete-Macias I, Zambrana-Torrelio CM, Solovyov A, Ojeda-Flores R, Arrigo NC, Islam A, Ali Khan S, Hosseini P, Bogich TL, Olival KJ, SanchezLeon MD, Karesh WB, Goldstein T, Luby SP, Morse SS, Mazet JA, Daszak P, Lipkin WI (2013) A strategy to estimate unknown viral diversity in mammals. MBio 4(5):e00598-e00613. doi:10. 1128/mBio.00598-13

27. Duffy MR, Chen TH, Hancock WT, Powers AM, Kool JL, Lanciotti RS, Pretrick M, Marfel M, Holzbauer S, Dubray C, Guillaumot L, Griggs A, Bel M, Lambert AJ, Laven J, Kosoy O, Panella A, Biggerstaff BJ, Fischer M, Hayes EB (2009) Zika virus outbreak on Yap Island, Federated States of Micronesia. N Engl J Med 360(24):2536-2543. doi:10.1056/NEJMoa0805715

28. Antia R, Regoes RR, Koella JC, Bergstrom CT (2003) The role of evolution in the emergence of infectious diseases. Nature 426(6967):658-661

29. Bhatt S, Gething PW, Brady OJ, Messina JP, Farlow AW, Moyes CL, Drake JM, Brownstein JS, Hoen AG, Sankoh O, Myers MF, George DB, Jaenisch T, Wint GR, Simmons CP, Scott TW, Farrar JJ, Hay SI (2013) The global distribution and burden of dengue. Nature 496(7446):504-507. doi:10.1038/nature12060

30. Herfst S, Schrauwen EJ, Linster M, Chutinimitkul S, de Wit E, Munster VJ, Sorrell EM, Bestebroer TM, Burke DF, Smith DJ, Rimmelzwaan GF, Osterhaus AD, Fouchier RA (2012) Airborne transmission of influenza $\mathrm{A} / \mathrm{H} 5 \mathrm{~N} 1$ virus between ferrets. Science 336(6088):1534-1541. doi:10.1126/science.1213362

31. de Graaf M, Fouchier RA (2014) Role of receptor binding specificity in influenza A virus transmission and pathogenesis. EMBO J 33(14):823-841

32. Brault AC, Powers AM, Ortiz D, Estrada-Franco JG, NavarroLopez R, Weaver SC (2004) Venezuelan equine encephalitis emergence: enhanced vector infection from a single amino acid substitution in the envelope glycoprotein. Proc Natl Acad Sci USA 101:11344-11349

33. de Lamballerie $X$ et al (2008) Chikungunya virus adapts to tiger mosquito via evolutionary convergence: a sign of things to come? Virol J 5:33. doi:10.1186/1743-422X-5-33

34. Brault AC, Huang CY, Langevin SA, Kinney RM, Bowen RA, Ramey WN, Panella NA, Holmes EC, Powers AM, Miller BR (2007) A single positively selected West Nile viral mutation confers increased virogenesis in American crows. Nat Genet 39:1162-1166

35. Smith DF, Cummings RD (2014) Investigating virus-glycan interactions using glycan microarrays. Curr Opin Virol 7C:79-87. doi:10.1016/j.coviro.2014.05.005

36. Matrosovich M, Tuzikov A, Bovin N, Gambaryan A, Klimov A, Castrucci MR, Donatelli I, Kawaoka Y (2000) Early alterations of the receptor-binding properties of $\mathrm{H} 1, \mathrm{H} 2$, and $\mathrm{H} 3$ avian influenza virus hemagglutinins after their introduction into mammals. J Virol 74(18):8502-8512

37. Jenkins CN, Pimm SL, Joppa LN (2013) Global patterns of terrestrial vertebrate diversity and conservation. Proc Natl Acad Sci U S A 110(28):E2602-E2610. doi:10.1073/pnas.1302251110

38. Foley DH, Rueda LM, Wilkerson RC (2007) Insight into global mosquito biogeography from country species records. J Med Entomol 44(4):554-567

39. Cumming GS (2000) Using habitat models to map diversity: panAfrican species richness of ticks (Acari: Ixodida). J Biogeogr 27(2):425-440

40. Guernier V, Hochberg ME, Guégan JF (2004) Ecology drives the worldwide distribution of human diseases. PLoS Biol 2(6):e141

41. Dunn RR, Davies TJ, Harris NC, Gavin MC (2010) Global drivers of human pathogen richness and prevalence. Proc Biol Sci 277(1694):2587-2595

42. Reynolds MG, Davidson WB, Curns AT, Conover CS, Huhn G, Davis JP, Wegner M, Croft DR, Newman A, Obiesie NN, Hansen GR, Hays PL, Pontones P, Beard B, Teclaw R, Howell JF, Braden Z, Holman RC, Karem KL (2003) Damon IK (2007) Spectrum of infection and risk factors for human monkeypox, United States. Emerg Infect Dis 13(9):1332-1339. doi:10.3201/eid1309.070175

43. Nasci RS (2014) Movement of chikungunya virus into the Western hemisphere. Emerg Infect Dis 20(8):1394-1395. doi:10. 3201/eid2008.140333

44. Jones KE, Patel NG, Levy MA, Storeygard A, Balk D, Gittleman JL, Daszak P (2008) Global trends in emerging infectious diseases. Nature 451:990-993

45. Myers N (1988) Threatened biotas: 'hot-spots' in tropical forests. Environmentalist 8(3):187-208

46. Perkins TA, Garcia AJ, Paz-Soldán VA Stoddard ST, Reiner RC Jr, Vazquez-Prokopec G, Bisanzio D, Morrison AC, Halsey ES, Kochel TJ, Smith DL, Kitron U, Scott TW, Tatem AJ (2014) Theory and data for simulating fine-scale human movement in an urban environment. J R Soc Interface 11(99). pii: 20140642. doi:10.1098/rsif.2014.0642

47. Mosha JF, Sturrock HJ, Greenwood B, Sutherland CJ, Gadalla NB, Atwal S, Hemelaar S, Brown JM, Drakeley C, Kibiki G, Bousema T, Chandramohan D, Gosling RD (2014) Hot spot or not: a comparison of spatial statistical methods to predict prospective malaria infections. Malar J 11(13):53. doi:10.1186/14752875-13-53

48. Moore SM, Monaghan A, Griffith KS, Apangu T, Mead PS, Eisen RJ (2012) Improvement of disease prediction and modeling through the use of meteorological ensembles: human plague in Uganda. PLoS ONE 7(9):e44431

49. Punjabi NH, Taylor WR, Murphy GS, Purwaningsih S, Picarima H, Sisson J, Olson JG, Baso S, Wangsasaputra F, Lesmana M, Oyofo BA, Simanjuntak CH, Subekti D, Corwin AL, Richie TL (2012) Etiology of acute, non-malaria, febrile illnesses in Jayapura, northeastern Papua. Indonesia. Am J Trop Med Hyg 86(1):46-51. doi:10.4269/ajtmh.2012.10-0497

50. Crump JA, Morrissey AB, Nicholson WL, Massung RF, Stoddard RA, Galloway RL, Ooi EE, Maro VP, Saganda W, Kinabo GD, Muiruri C, Bartlett JA (2013) Etiology of severe non-malaria febrile illness in Northern Tanzania: a prospective cohort study. PLoS Negl Trop Dis 7(7):e2324. doi:10.1371/journal.pntd. 0002324

51. Schoepp RJ, Rossi CA, Khan SH, Goba A, Fair JN (2014) Undiagnosed acute viral febrile illnesses. Sierra Leone. Emerg Infect Dis 20(7):1176-1182. doi:10.3201/eid2007.131265

52. Swoboda P, Fuehrer HP, Ley B, Starzengruber P, Ley-Thriemer K, Jung M, Matt J, Fally MA, Mueller MK, Reismann JA, Haque R, Khan WA, Noedl H (2014) Evidence of a major reservoir of non-malarial febrile diseases in malaria-endemic regions of 
Bangladesh. Am J Trop Med Hyg 90(2):377-382. doi:10.4269/ ajtmh.13-0487

53. Arrigo NC, Briese T, Calisher CH, Drebot MA, Hjelle B, LeDuc JW, Powers AM, Repik PM, Roehrig JT, Schmaljohn CS, Tesh $\mathrm{RB}$, Weaver SC (2012) Recommendations for publication of viral genetic data and sample access for novel viruses and strains. Am J Trop Med Hyg 86(2):189-191. doi:10.4269/ajtmh.2012.11-0523

54. Lecuit M, Eloit M (2013) The human virome: new tools and concepts. Trends Microbiol 21(10):510-515. doi:10.1016/j.tim. 2013.07.001
55. Dalianis T, Hirsch HH (2013) Human polyomaviruses in disease and cancer. Virology 437(2):63-72. doi:10.1016/j.virol.2012.12.015

56. Smith I, Wang LF (2013) Bats and their virome: an important source of emerging viruses capable of infecting humans. Curr Opin Virol 3(1):84-91. doi:10.1016/j.coviro.2012.11.006

57. Cleaveland S, Haydon DT, Taylor L (2007) Overviews of pathogen emergence: which pathogens emerge, when and why? Curr Top Microbiol Immunol 315:85-111 